\title{
El diseño como herramienta de análisis e intervención de la realidad de las mujeres en una localidad pequeña ${ }^{1}$
}

\author{
Design as a tool for analysis and intervention of women's reality \\ in a small town
}

Cómo citar:

Taibo, J., 2021. El diseño como herramienta de análisis e intervención de la realidad de las mujeres en una localidad pequeña. Designia, 8(2), 63-91.

\author{
${ }^{1}$ Facultad de Arquitectura, Planeamiento y Diseño, Universidad \\ Nacional de Rosario, Argentina. Reflexión sobre trabajo de investi- \\ gación finalizado, en el marco del Taller de Proyecto y Evaluación \\ Final a cargo de Javier Veraldi, del Ciclo de Complementación \\ Curricular de Licenciatura en Diseño de Comunicación Visual \\ (Resol. C. S. № 047/14CS). \\ * Máster en Comunicación y Cultura (2020) por la Universidad de \\ Sevilla, España. Licenciado en Diseño de Comunicación Visual (2017) \\ por la Universidad Nacional de Rosario, Argentina. Administrador \\ de Empresas de Diseño (2015) y Diseñador Gráfico y Publicitario \\ (2011) por el Colegio Universitario IES Siglo 21, Córdoba, Argentina. \\ E-mail: taibojonathan@gmail.com \\ ORCID: https://orcid.org/0000-0003-3008-2206
}

\section{Palabras clave:}

Diseño estratégico, emprendedurismo, empoderamiento, género, territorio

Key words:

Strategic design, entrepreneurship, empowerment, gender, territory

Recibido: 08/04/2020

Aceptado: 02/09/2020

Resumen:

Este artículo se presenta como una reflexión sobre el planteamiento de una propuesta de diseño estratégico, surgida a partir de una investigación en el territorio llevada a cabo en el año 2016, y propone una discusión sobre sus resultados. Se toma como objeto de estudio a la organización Proyecto Esperanza Milani, mujeres autoconvocadas de la localidad de Manfredi, Provincia de Córdoba, Argentina. En primer lugar, se analiza y contextualiza tanto a la 
agrupación como al marco conceptual para el abordaje disciplinar. Luego, se amplía el estudio con búsqueda de datos (a través de entrevistas guiadas o "pautadas" y sondeo de opinión) para la comprensión situada del pueblo. Por último, se retorna a la organización con el desarrollo de una estrategia de diseño para la intervención local: desde un enfoque en perspectiva de género sobre el emprendedurismo y el empoderamiento, la comunicación de la marca personal y la inserción de la mujer en el entramado socio-productivo.

\section{Abstract:}

This article is presented as a reflection on the approach of a strategic design proposal, which arose from research carried out in the territory in 2016, and proposes a discussion on its results. The organization Proyecto Esperanza Milani, self-convened women from Manfredi's town (Córdoba Province, Argentina), is taken as the object of study. Firstly, both the grouping and the conceptual framework for the disciplinary approach are analyzed and contextualized. Then, the study is expanded with data searching (through guided or "in-depth" interviews and an opinion survey) for a town's situated understanding. Lastly, the organization is revisited with the aim of developing a design strategy for local intervention: from a gender perspective approach about entrepreneurship and empowerment, personal brand communication and the insertion of women in the socio-productive environment. 


\section{INTRODUCCIÓN}

En muchas ocasiones, se habla de diseño estratégico y de la puesta en valor del territorio, a partir de la aplicación de modelos ya existentes o esquemas previos, sin llegar al desarrollo de una perspectiva local real, situada. En términos de Franco, Muñóz y Lesmes (2008), esta concepción,

[...] hace un análisis de las capacidades del diseño en el sector estratégico, proyectual y operativo de la organización industrial, plantea esquemas de interdisciplinariedad y trabajo en equipo, control sobre los procesos y en general todo lo necesario para llevar a cabo las estrategias, los proyectos que las componen y el análisis y toma de decisiones sobre los proyectos por implementar y el control sobre las actividades y el tiempo basados siempre en las necesidades de los usuarios. (pp. 99-100).

El presente artículo se propone como una reflexión acerca del resultado de una experiencia de trabajo que inicia su recorrido en el análisis, contextualización y revisión teórica de los conceptos fundantes sobre el campo disciplinar y profesional del diseño en el territorio. Luego, recupera la labor de campo llevada a cabo en una investigación del año 2016, que incorpora un enfoque para la búsqueda y el diagnóstico en perspectiva de género sobre el empoderamiento y el emprendedurismo, en una localidad específica: Manfredi.

Tras este recorrido, se retorna a la disciplina a partir del planteo de un posicionamiento. Es decir, desde la toma de partido bajo una idea que desarrolla un diseñador en particular. En palabras de María del Valle Ledesma (2003):

\footnotetext{
El diseño gráfico al estar volcado hacia la sociedad, al tener como fin la inscripción en su dinámica compleja y contradictoria, siempre está incluido en un sistema de poder y contrapoder, de opresión interna y externa, de exclusiones y permeabilidades que delimitan la acción del diseñador: por lo tanto, cada vez que actúa, el diseñador toma partido.
}

Hay un lugar de la disciplina, pero también hay un partido que toma el diseñador quien, antes que diseñador es hombre. (p. 10). 
Desde allí, se propondrá el desarrollo de una estrategia de diseño para la intervención local, reinterpretando la noción de emprendimiento, la comunicación de la marca personal y la inserción de la mujer en el entramado socio-productivo.

\section{[...] el diseño reconstruye un patrimonio simbólico local, al nivel del producto, unidad productiva o colectivo social que se relaciona con las ideas-valor que refleja este sentido de comunidad, y lo expresa como significado en un sistema, que llamamos el sistema del producto, para acreditarlo como valor. (Galán, 2014, p. 55).}

\section{OBJETO DE ESTUDIO}

Se tomó como objeto de estudio de la investigación a la estructura y comunicación -interna y externa - de la organización no gubernamental Proyecto Esperanza Milani. La misma tiene carácter informal (se configuraba como un conjunto de mujeres autoconvocadas, sin registro legal como personería jurídica) y como propósito, a partir de talleres de capacitación, el configurar un espacio para el aprendizaje colectivo y el intercambio social de experiencias de conocimiento.

Comienza sus actividades en el año 2010, con el dictado del Taller de Muñecos en Tela, en la localidad de Manfredi, provincia de Córdoba, Argentina. Y por tanto, el público al que apuntaban eran todas las mujeres del pueblo, mayores de 15 años. 

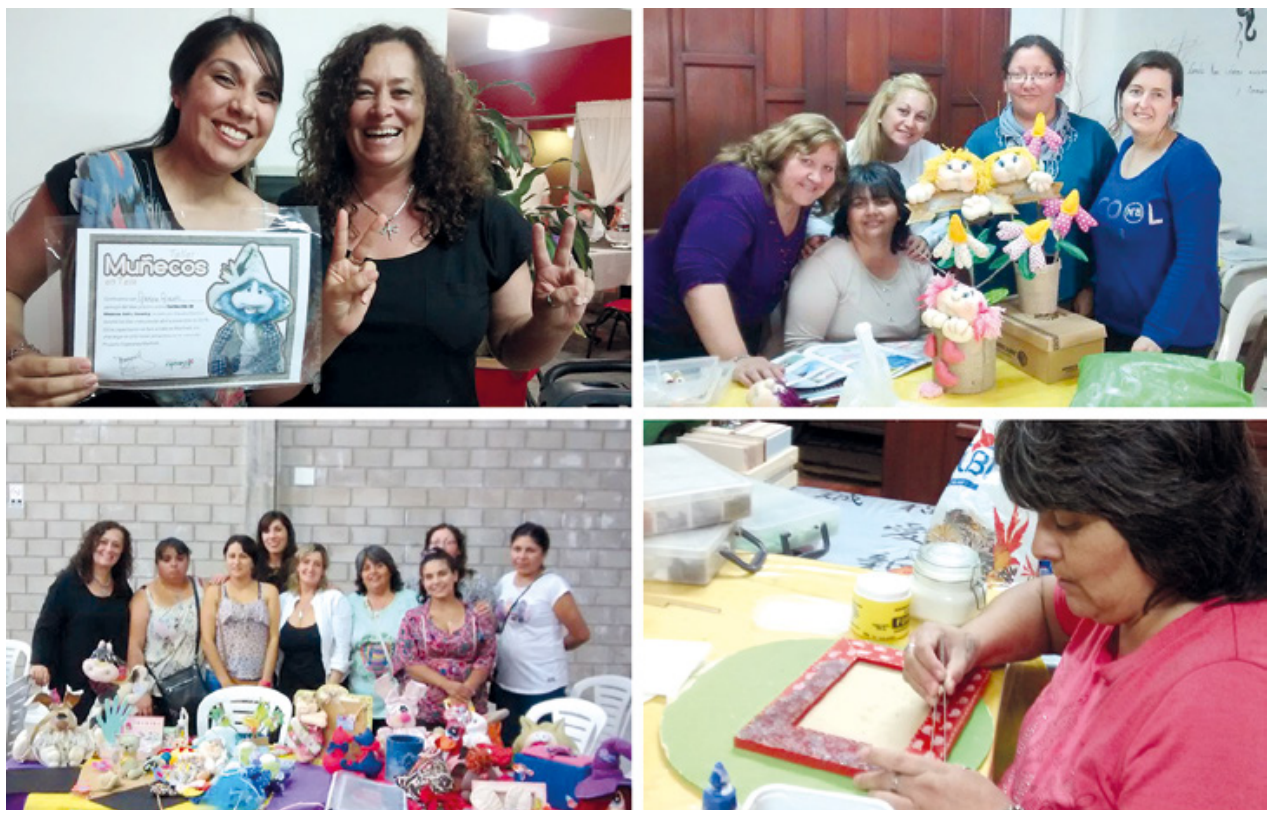

Figura 1. Imágenes de algunas de las mujeres que participaron del taller.

Fuente: Proyecto Esperanza Milani.

Considerábamos que el abordaje de esta agrupación era relevante para llevar a cabo un análisis de diseño en el territorio, desde la perspectiva del diseño para el desarrollo local, en términos de Beatriz Galán (2014):

\section{El diseño es entonces la construcción local de la sustentabilidad, a través de proyectos, en los ámbitos de autoafirmación de los individuos, sus ámbitos comunitarios, reinterpretándola localmente. (p.35).}

Los cursos que dictaban eran pensados como educación no formal y de manera interdisciplinaria, con la ambición de ir sumando actividades que incluyeran a todos los sectores de la sociedad, en un proyecto de solidaridad con "el otro". Lo que también proponía ir generando distintas formas de expresión y, a la vez, la construcción de espacios donde se manifestara la cultura local. La cual contemplaría, en términos de Hendon (1980), el entorno donde participan artistas y artesanos; toda organización e institución que promueva las artes en la localidad (museo, escuelas de danzas y pintura, entre otras); diferentes formas de expresiones musicales y escritas de autores oriundos de Manfredi; emprendimientos gastronómicos o comerciales que promueven el consumo en el pueblo, por ejemplo; la arquitectura y el espacio público; entre otros. 


\subsection{Contextualización}

La localidad de Manfredi se encuentra a la vera de la Ruta Nacional Número 9, a 68 kilómetros de la ciudad de Córdoba Capital. Tiene como vecinas a la ciudad de Oncativo (9 km al Sur) y a las localidades de Laguna Larga (9 km al Norte). Pertenece al Departamento Río Segundo y se caracteriza desde su fundación, por las actividades económicas y de producción que ponen al hombre en relación con el desarrollo de la agricultura.

Contaba con un número estimado de 1000 habitantes aproximadamente. Según datos oficiales de la Dirección General de Estadísticas y Censos del Gobierno de la Provincia de Córdoba, en el Censo Nacional del año 2010, la localidad registraba un total de 964 personas (483 hombres y 481 mujeres).

Entre las fuentes de trabajo locales, se destacaban las siguientes instituciones o empresas principales: Estación Experimental INTA; Municipalidad y entes municipales (Centro de Salud, Centro de Cuidado Infantil, Hogar de Día, etc.); Cooperativa de obras, servicios públicos y sociales de Manfredi; Planta cerealera ACA; Asociación Civil de Transportistas de Manfredi. Además, hay fuentes de trabajo como emprendimientos más pequeños que poseen desde 1 a 7 empleados (supermercado, carnicería, comedores, etc.). Trabajadores particulares había muy pocos, entre los que destacaban los del rubro Transporte de Cereales.

En el año 2016, en la localidad se observa el desarrollo de pequeños comercios de ramos generales, varios instalados en los domicilios particulares debido, en algunos casos puntuales, a la desocupación y a los cambios operados en las relaciones laborales y en la tecnificación del trabajo rural y, en otros casos, como complemento del ingreso familiar.

A nivel Municipal, se llevaban a cabo desde agosto de 2016 capacitaciones en Gestión Administrativa Contable y en Instalaciones Eléctricas Domiciliarias (sólo para hombres) en el marco del CEDER (Centro de Desarrollo Regional, Programa Provincial). En este contexto, se otorgaban Micropréstamos para beneficiarios de los cursos de capacitación profesional o de oficios (programa que baja también desde el Gobierno Provincial). 
A nivel Provincial, pero que todavía no había llegado a la localidad al momento del estudio, se encontraba en vigencia el Programa Córdoba Con Ellas. El abordaje de la cuestión de género se enfocaba de la siguiente manera:

El Gobierno de la Provincia de Córdoba entiende que en la familia, la mujer es el sostén moral que asume el rol principal en lo económico y social; es transmisora de valores y la única capaz de reconstituir los vínculos rotos. La mujer es el núcleo de referencia de las necesidades de su grupo, y es también mediadora entre las personas de su familia y el entorno; es la mujer la que decide hacer el bien y ayudar al otro, convirtiéndose en el pilar básico de cohesión social. ${ }^{2}$

\section{ESTADO DE LA CUESTIÓN}

Se considera que todo el proceso de la investigación se enmarcó en el paradigma constructivista, en tanto se realizó un esfuerzo por interpretar la evolución de determinados fenómenos y conceptos, en contexto (Ramos, 2015). Es decir, en su implicación epistemológica, se entendía que:

[...] los constructivistas toman una posición subjetivista donde el investigador y el investigado son fusionados dentro de una sola entidad. Los hallazgos son creaciones del proceso de interacción entre los dos. Si las realidades existen solamente en la mente de los respondientes, las interacciones subjetivas parecen ser la única forma de acceso a estas. (Flores Fahara, 2004, p. 5).

Dentro de la teoría del diseño de comunicación, se abordó el concepto de diseño que propone Jorge Frascara (2012) como punto de partida:

El diseño es en general entendido como el producto físico derivado de la actividad, pero la actividad misma es ignorada. [...] Mientras que el público tiende a ver «diseño» como referido a objetos, los diseñadores tienden a usar la palabra para referirse al acto de diseñar, y ven al producto como el resultado final de un largo camino. Diseñar, para el profesional de hoy, es una actividad intencional. [...] Diseñar es coordinar una larga lista de factores humanos y técnicos, trasladar lo invisible en visible, y comunicar. Diseñar implica evaluar, implementar conocimientos, generar nuevos conocimientos, y usar la experiencia para guiar la toma de decisiones. (p. 23).

${ }^{2}$ Extracto recuperado de http://empleo.cba. gov.ar/programas-deempleo/cordoba-conellas/ [Consultado el 16 de diciembre de 2016]. 
Entendiendo que también nos permitió avanzar sobre ciertas dinámicas y prácticas propias del diseño estratégico y la innovación, en tanto se buscaron soluciones que se caracterizan por:

[...] la recombinación creativa de los activos ya existentes (desde el capital social al patrimonio histórico, desde la artesanía tradicional, a la tecnología avanzada y accesible) y cuyo objetivo consiste en alcanzar metas socialmente reconocidas pero de una manera completamente nueva. (Manzini, 2015, p. 14).

La interpretación que dió a lo local, en el contexto de la globalización, también se recuperó de Ezio Manzini (2015):

La pequeña escala y la interconexión que caracterizan a las organizaciones sociales les permiten arraigar en un lugar de manera más profunda. Al mismo tiempo, al estar interconectadas, quedan abiertas a flujos globales de ideas, informaciones, personas, bienes y dinero. Los promotores y participantes tienden a buscar este equilibrio entre lo local y lo abierto que conduce a una suerte de localismo cosmopolita, capaz de generar un nuevo sentido de lugar. (p. 34).

Continuando con la ambición de proponer un marco teórico interdisciplinar, es necesario expresar que entendimos el abordaje desde una perspectiva de género, en tanto se realizó un profundo ejercicio de análisis estableciendo relaciones entre la rutina diaria de las mujeres y cómo se desenvuelven para conciliar su vida laboral y familiar.

[...] a finales de la década de los 80 del siglo XX [...] la denominada perspectiva de género actuó como un paraguas acogedor de una revisión teórico-conceptual que, entre otros muchos logros, partió de conceptos percibidos en singular para alcanzar el plural. Dicho de otro modo, más allá de la diversidad de enfoques existentes, el sujeto quasi universal y homogéneo «mujer» devino, según esa perspectiva, en el colectivo «mujeres» donde, posteriormente, fue posible observar la heterogeneidad e incluso las desigualdades que lo presiden. Asimismo, según ese enfoque, el concepto de trabajo aceptó el plural, gracias al reconocimiento de la existencia de un trabajo doméstico o reproductivo. (Torns, 2008, p. 53). 
Esta perspectiva, deja en evidencia la subordinación en la participación de las mujeres en las sociedades contemporáneas. Como menciona Irma Arriagada (2005) en su artículo "Dimensiones de la pobreza y políticas desde una perspectiva de género", en las limitaciones para el acceso "...a la propiedad y al control de los recursos económicos, sociales y políticos" (p. 104).

Su recurso económico fundamental es el trabajo remunerado, al cual acceden en condiciones de mucha desigualdad, dada la actual división del trabajo por género en que las mujeres asumen el trabajo doméstico y el cuidado de los hijos de manera casi exclusiva, y la persistencia de formas tradicionales y nuevas de discriminación para el ingreso y permanencia de las mujeres en el mercado laboral. (Arriagada, 2005, pp. 104-105).

Por último, cuando hablábamos de "emprendedurismo", estábamos haciendo referencia a la personalidad y al campo donde interviene el sujeto que conocemos como "emprendedor":

[...] al hablar de función emprendedora se alude a las características que tiene una persona que emprende negocios, es decir, del emprendedor. (Jasso Villazul, 2011, p. 93). 


\section{PREGUNTA Y OBJETIVOS DE LA INVESTIGACIÓN}

Se partió de una única pregunta general: ¿es posible la elaboración de una propuesta de diseño estratégico en el territorio, desde el empoderamiento con perspectiva de género, en localidades pequeñas?

Para el abordaje territorial, que luego sería punto de partida para la propuesta de diseño, se siguió con el planteo de un objetivo general, que fue el de profundizar sobre la situación laboral y la cuestión género, en las mujeres mayores a 15 años de la localidad de Manfredi, durante los meses octubre y noviembre del año 2016. Además, se enumeraron seis objetivos específicos, a saber:

1. Conocer si existen espacios de capacitación laboral o de oficios para la mujer en Manfredi y si asisten a esos espacios.

2. Averiguar sobre los conocimientos que poseen las mujeres de Manfredi sobre emprendedorismo.

3. Conocer si existen políticas públicas que acompañen a la mujer en el desarrollo emprendedor a nivel municipal, provincial y nacional que no se hayan detectado en la etapa de contextualización.

4. Cuantificar el porcentaje de mujeres que conocen sobre dichas políticas y el porcentaje de mujeres que accede o ha accedido a algún plan de este tipo.

5. Conocer si las emprendedoras se vinculan con otras organizaciones y, en caso positivo, cómo se da esa vinculación.

\section{METODOLOGÍA}

Se plantearon dos instancias de abordaje, con metodologías de trabajo de campo diferente, para realizar a posterior una triangulación de los testimonios y datos obtenidos.

\footnotetext{
A la pregunta metodológica, el constructivismo considera que las construcciones individuales son derivadas y refinadas hermenéuticamente, y comparadas y contrastadas dialécticamente, con la meta de generar una (o pocas) construcciones sobre las cuales hay un consenso substancial. (Flores Fahara, 2004, p. 5).
} 
En un primer momento, se plantearon entrevistas guiadas o "pautadas" a la coordinadora, alumnas y egresadas del taller. Este tipo de instrumento, caracterizado por un nivel bajo de formalización, apuntaba a generar un diálogo profundo presentando "...los hechos en toda su complejidad, captando no sólo las respuestas a los temas elegidos sino también las actitudes, valores y formas de presentar a los entrevistados". (Sabino, 2002, p. 109). Para conocer en cada caso la vivencia y experiencia en Proyecto Esperanza Milani, pero además, para conocer su vinculación con el contexto laboral local. Este acercamiento, también buscaba dar cuenta del relato personal de sus vidas y sus aspiraciones personales.

En un segundo momento, ya habiendo tenido una aproximación desde la mirada de los actores internos, se llevó a cabo un sondeo de opinión para conocer la realidad laboral de las mujeres del pueblo y así partir de una tendencia aproximada sobre la situación. Su intención fue conocer una tendencia para acompañar lo que se intuye por vivir en la localidad (falta de fuentes de trabajo, a nivel local, para la mujer).

\subsection{Muestreo}

Para las entrevistas guiadas o "pautadas", se seleccionó en primer lugar a la coordinadora del taller. Luego, se seleccionaron de forma intencional a tres alumnas y tres egresadas.

Para el sondeo de opinión, se tomó una muestra no probabilística casual, a partir de un cuestionario puesto a disposición en redes sociales. Se relevó un total de 28 testimonios. 


\section{RESULTADOS}

Se encontró que a finales de 2016, existían espacios de capacitación para las mujeres jubiladas o mayores de 50 años, en el marco de un taller de manualidades que se dictaba semanalmente en el Centro de Jubilados de Manfredi. Por otra parte, el CEDER brindaba dos capacitaciones pero ninguna estaba enfocada en el desarrollo de la mujer. De hecho, un curso de instalaciones eléctricas era destinado específicamente a hombres. Otro de secretariado administrativo, para ambos sexos. Este último, también era restrictivo en el sentido de que se necesitaba una base de conocimientos para acceder.

Además, se brindaron capacitaciones en el marco de la entrega de microcréditos del Gobierno de la Provincia de Córdoba, pero de unas aproximadamente 25 personas sólo tres habían presentado sus proyectos hasta el momento.

En ese contexto, Proyecto Esperanza Milani era el único espacio de capacitación que enfocaba sus actividades al desarrollo emprendedor de la mujer y era reconocido por las mujeres como un espacio de encuentro, para compartir experiencias y para alejarse de la rutina diaria.

Respecto a los conocimientos que poseían las mujeres de Manfredi sobre el emprendedurismo, de 28 encuestadas, el 75\% respondió considerarse una "mujer emprendedora" y el 25\% restante tal vez, lo que nos arrojó un dato favorable con respecto a la actitud positiva de las mismas frente al trabajo. Pero sólo el 28,6\% afirmó haber realizado alguna vez una capacitación sobre emprendedurismo, lo que nos planteó una serie de cuestionamientos, ya que deberían haber estado interesadas en capacitarse para poder llevar adelante sus proyectos. Cotejando todos los datos obtenidos, la realidad exponía que se habían impartido muy pocas capacitaciones en la localidad sobre estos temas y, cuando se concretaron, muchas de las mujeres no se enteraron (lo mismo sucedió con la entrega de microcréditos).

Profundizando sobre la posibilidad de que existieran políticas públicas que acompañaran a la mujer en el desarrollo emprendedor a nivel municipal, provincial y nacional, se corroboraron los planes encontrados en la contextualización de la investigación, pero en la realidad de implementación y bajada desde el municipio se descubrieron algunas falencias. Por ejemplo, falta de información sobre estos planes o falta de seguimiento de los interesados (lo que hacía que terminaran desertando).

En las encuestas se evidenció conocimiento de una de las mujeres del plan provincial Salas Cuna: 
La red provincial de Salas Cuna, proyecto articulado con ONGs de inserción comunitaria y con Municipios, contempla espacios destinados al cuidado y la protección de niños y niñas de 45 días a 3 años de sectores vulnerables. Las Salas Cuna tienen dos objetivos concretos que se complementan: Por un lado, contribuir al desarrollo psico-social de los niños y niñas invirtiendo en la estimulación temprana, para garantizar el desarrollo de todo su potencial. A su vez, la sala Cuna le brinda a la mujer la tranquilidad del cuidado y contención de sus hijos, mientras trabaja o asiste a la escuela. Contribuye así a la inserción social y laboral de las mujeres. ${ }^{3}$

De las cuatro mujeres entrevistadas, dos manifestaron no conocer sobre estos planes. De las dos que conocían, una estaba en proceso de armado de su plan de negocios para postular al microcrédito. Luego, de 28 mujeres encuestadas, el 75\% manifestó que no creía que en Manfredi existieran en ese momento políticas que acompañaran a la mujer emprendedora. Muchas evidenciaron algunas iniciativas, pero pocos resultados concretos (en las respuestas se pudo percibir cierto descreimiento de las políticas públicas, asociándolas a "dádivas" y que eran entregadas a determinadas personas que accedían a la información por acercamiento al municipio).

Entendiendo la existencia de otros tipos de asociaciones a nivel local, las emprendedoras manifestaron vincularse principalmente a través de la Asociación de Artesanos, como grupo a partir del cual hacían sinergia para recorrer muestras y exposiciones en Manfredi y localidades vecinas. Aunque también reconocieron que esa interacción hacía meses que sólo se daba por un grupo de Whatsapp y no habían podido reunirse personalmente.

Para cerrar, a partir de las entrevistas y encuestas se evidenció un posicionamiento de las mujeres frente a su situación $-\mathrm{y}$ la de las mujeres de la localidad en general- recurrente. En general sentían que la mujer no tenía posibilidades de crecimiento en la localidad y que el trabajo siempre estaba relacionado a la limpieza (ya sea en su casa, cuidando de su familia, como en las empresas y negocios del pueblo u otros hogares).

También manifestaron que, en la localidad, el rol de la mujer como ama de casa se venía transmitiendo de generación en generación: era el rol en el que se reconocían y sus esposos y pares conocían y validaban.

Además, se expusieron casos donde estaba dado por hecho que la mujer no podía realizar determinado tipo de trabajos, que sólo estarían reservados para los hombres. Pero ellas lo abordaban con una posición reflexiva y crítica al respecto.

${ }^{3}$ Extracto recuperado de http://www.cba.gov.ar/ salas-cuna/ [Consultada el 16 de diciembre de 2016]. 


\section{DISCUSIÓN}

En algunas de las respuestas a entrevistas se fueron resaltando expresiones donde las mujeres podrían haber dejado en evidencia que no veían el trabajo que realizaban emprendiendo como un "trabajo real", que las dignifica. Expresiones como: "Como no puedo trabajar, hago estas cosas" o "hago eso y nada más, aparte de ser madre". Frente a otros pensamientos que las manifiestan con una postura crítica ante los patrones culturales, como que "a una carta de porte la puede hacer cualquiera, no sólo un hombre", o que ellas tranquilamente podrían salir a hacer tareas de mantenimiento en las calles pero ni siquiera se las tiene en cuenta para esos puestos.

Entonces, como recomendación a priori se propuso abordar estos temas desde Proyecto Esperanza Milani, trabajando el empoderamiento femenino a nivel emocional (para enfatizar ese pensamiento crítico que ya manifestaban) pero sobre todo vinculándolo con sus habilidades para que reconocieran y se reconocieran en su trabajo y como emprendedoras.

En este sentido, se propuso la posibilidad de pensar más talleres sobre estas temáticas (que se repitieran con cierta periodicidad) o incluso comenzar a trabajarlos transversalmente con los contenidos del Taller de Muñecos en Tela. Es decir, desde el hacer práctico ir ya pensando o incentivando a imaginar/proyectar cómo sería su emprendimiento. Qué necesitaban, dónde podían conseguir financiamiento, a quiénes debían investigar como referentes.

Todas estas iniciativas en un marco del compartir experiencias, partiendo de que todas ellas reconocieron que asistían o habían asistido al taller en busca de un lugar para salir de la rutina y para interactuar con otras personas que tenían prácticamente los mismos gustos e intereses.

Por otra parte, fue evidente que en el contexto local las emprendedoras no estaban pudiendo depositar su producción como proveedoras (no había comercios donde pudieran vender como mayoristas sus productos ni industrias que las requirieran por sus habilidades) y les costaba también comercializar a consumidor final, porque la demanda no era suficiente como para que todas pudieran subsistir vendiendo productos que competían entre ellos. Además de que debían disminuir los precios porque no había una valoración como producto industrial, seguían siendo percibidos como artesanías o manualidades (trabajo no calificado que se hace a pedido). 
Entonces, una segunda recomendación desde el diseño estratégico, fue pensar de qué manera se podría pensar y generar un actor que incluya a esta parte de la población de Manfredi, mujeres emprendedoras egresadas del taller, como mano de obra y que no sólo las incorpore al sistema productivo sino que las empodere desde el reconocimiento y la dignificación de sus conocimientos y habilidades.

\subsection{Posicionamiento: "Compartiendo empoderamiento"}

Este posicionamiento se construyó, en primer lugar, a partir de un sentimiento que manifestaron experimentar las mujeres que asistían al taller: el compartir. El compartir hace referencia a dar un recurso o espacio a otras personas en común. Pero, además, implica que esas personas van a hacer un uso alternativo o un disfrute simultáneo de ese bien finito. En la idea de la construcción del goce, es necesario recordar que siempre están involucradas al menos dos personas. Y en este sentido, pensar que esta construcción se dará en conjunto.

Roland Barthes (1993), en su escrito "El placer del texto", hace una distinción entre textos de placer y textos de goce. No es necesario ahondar en ambas definiciones elaboradas por el autor, pero podemos hacer mención de un pequeño fragmento:

\section{Si leo con placer esta frase, esta historia o esta palabra es porque han sido escritas en el placer (este placer no está en contradicción con las quejas del escritor). Pero ¿y lo contrario? ¿Escribir en el placer, me asegura a mí, escritor, la existencia del placer de mi lector? De ninguna manera. Es preciso que yo busque a ese lector (que lo "rastree") sin saber dónde está. Se crea entonces un espacio de goce. No es la "persona" del otro lo que necesito, es el espacio: la posibilidad de una dialéctica del deseo, de una imprevisión del goce: que las cartas no estén echadas sino que haya juego todavía. (p.12)}

Dicho extracto posicionó la propuesta de diseño de comunicación en un lugar de interacción, de intercambio con el otro, en la elaboración de lo que disfrutamos (en plural, porque es en conjunto). En las experiencias vividas y por vivir en el taller, entonces, no había que dejar de pensar en esa construcción que es histórica y que, a su vez, estaba en constante crecimiento (era potencial). Se nutría de las experiencias y saberes de las mujeres que asistían desde hace años, pero también de las mujeres que recién comenzaban y que iban instalando nuevos temas de discusión que ampliaban los horizontes de lo conocido. Y esto era un pilar fundamental para que Proyecto Esperanza Milani creciera y no fuera visto como un grupo de mujeres determinado, sino que cualquiera podía ser parte. 
Por otro lado, se habló de empoderamiento en los términos de la Organización de Naciones Unidas (ONU):

\section{Un proceso mediante el cual tanto hombres como mujeres asumen el control sobre sus vidas: establecen sus propias agendas, adquieren habilidades (o son reconocidas por sus propias habilidades y conocimientos), aumentando su autoestima, solucionando problemas y desarrollando la autogestión. Es un proceso y un resultado. ${ }^{4}$}

La idea de "compartiendo empoderamiento", entonces, tenía que ver con una toma de partido en la que se pensaba que las mujeres del pueblo debían tener una posibilidad para tomar el control de su realidad diaria. Y que el germen de dicha posibilidad estaba en el intercambio con otras mujeres, que les permitiera reconcerse como grupo pero, sobre todo, que les posibilitara identificarse con lo que hacían y realizarse en su trabajo, percibiéndolo como una actividad profesional que estaba inserta en el sistema productivo y no como una actividad de "ocio" o como "complemento" del trabajo del hombre y de la economía del hogar.

\subsection{Interrogantes para la propuesta de diseño}

¿Cómo hacer de ese "compartir", salir de la rutina que planteaban las mujeres, una verdadera herramienta de empoderamiento? ¿Cómo "institucionalizar" a la comunidad de mujeres emprendedoras para que fueran reconocidas como tales? ¿Podría darse a través de la conformación de una organización o empresa que vendiera un producto tangible que la sociedad demanda? ¿Era posible generar una política al estilo "asignación universal por hijo" que permitiera a la mujer tener el tiempo que necesita para asistir al taller?

${ }^{4}$ Extracto recuperado de http://www.unwomen.org/ es/partnerships/businessesand-foundations/womensempowerment-principles [Consultada el 16 de diciembre de 2016].

\section{ESTRATEGIA DE DISEÑO PARA LA INTERVENCIÓN EN EL TERRITORIO}

Se propuso el abordaje desde el objetivo elaborado por Reinaldo Leiro (2006) para toda estrategia de comunicación, donde lo que se especifica “...es que el mercado detecte e interprete que existe una manera de ser específica de la empresa" (p. 154). Así, se identificaron, a partir de la investigación, diferentes niveles en la comunicación de Proyecto Esperanza Milani sobre los cuales actuar. 


\subsection{Estructura y comunicación interna de la organización}

Entre los principales objetivos de este nivel, se encontraban lograr una descentralización de las actividades para que no recayeran todas en la coordinadora; desarrollar un esquema que permitiera la incorporación de voluntarias que se especializaran en diferentes áreas, que pudieran supervisar, para lograr un seguimiento y mayor integración; comenzar un proceso de institucionalización como Asociación Civil o Fundación.

\section{Una nueva estrategia de largo plazo debe hacer pensar en el diseño de la organización. Es necesario realizar los cambios y ajustes dentro de los equipos de trabajo, de acuerdo con los nuevos proyectos. El recurso humano, siendo el más importante, debe estar correctamente distribuido según los nuevos objetivos y estrategias. (Sol, 1999, p.143).}

En este sentido, se sugirió una estructuración hacia un tipo de organización, en términos de Sol, "Departamental federal: organizada como unidades estratégicas de negocios. Un gerente está a cargo de cada negocio y tiene su propio cuadro de resultados” (obra citada, p. 144). En Proyecto Esperanza Milani: “Unidades Estratégicas de Abordaje del Empoderamiento" (en adelante "UEAE”). Las mismas estuvieron basadas en el documento "Principios para el Empoderamiento de las Mujeres: la igualdad es buen negocio" (colaboración entre ONU Mujeres y el Pacto Mundial de Naciones Unidas, publicado en 2011) y se titularon:

\subsubsection{Promoción de la equidad de género}

Se proponía la capacitación y orientación de una voluntaria en la cuestión de género, para que pudiera asesorar a las demás talleristas sobre cómo incorporar temáticas de manera transversal en sus clases. Además, sería la encargada de la organización anual de las jornadas por el “Día Internacional de la Eliminación de la Violencia contra la Mujer", pensadas para cada 25 de noviembre, continuación de una experiencia exitosa que llevó adelante Proyecto Esperanza junto a la Fundación Suyai en el año 2014 (pero que no volvió a repetirse).

La descentralización, tanto para el asesoramiento a otras talleristas como para la organización del evento, haría más factible la posibilidad de una continuidad y periodicidad, pensando que a futuro se convirtiera ésta en una fecha recordable por los miembros de la localidad y de directa asociación a la organización Proyecto Esperanza Milani. 


\subsubsection{Salud y trabajo}

Se contemplaba la creación de una UEAE que se especializara en la investigación de Programas y Planes de Gobierno pensados para la mujer, la posibilidad de acceder a dichos planes y cómo gestionarlos a través de Proyecto Esperanza Milani. Las personas involucradas deberían establecer vínculo con los diferentes niveles gubernamentales para el acceso a mayor información y trámites correspondientes.

Se proponía, además, una investigación en profundidad de las condiciones laborales de la mujer en el pueblo que permitiera elaborar una estadística que sirviera para exigir respuestas a un municipio, que no estaba implementando las políticas Provinciales o Nacionales, como así tampoco elaborando sus propias políticas de asistencia.

Esta unidad se daba con anterioridad como Mesa de Gestión Manfredi, un espacio político de la agrupación Frente para la Victoria con la colaboración de una Trabajadora Social, a través del cual se gestionaba Monotributo Social, Asignación Universal por Hijo, etc. pero que con el cambio de Gobierno a nivel nacional en 2015 no se pudo seguir sosteniendo.

\subsubsection{Educación y desarrollo profesional}

Esta era la UEAE sobre la que más fuertemente venía trabajando Proyecto Esperanza Milani en sus cinco años, a través del Taller de Muñecos en Tela principalmente. Lo que se sugirió fue una gestión para la incorporación de otros talleres que ampliaran la oferta educativa, a través de la creación de un sistema de voluntariado con las alumnas y egresadas, que habían demostrado interés en seguir vinculadas al espacio. Y, por sobre todo, un trabajo activo en conjunto con la UEAE de emprendedurismo.

\subsubsection{Emprendedurismo}

Por último, se pensó en un agente capacitado para el acompañamiento de las mujeres que asistían a los talleres en la elaboración de sus planes de negocio y en la implementación de los mismos. 
Se planteó, por un lado, la elaboración de un documento base sobre el que pudieran estructurarse todas las iniciativas de las alumnas (un documento como plantilla para completar con las diferentes etapas). Se acompañaría el mismo con una serie de capacitaciones mensuales generales $\mathrm{y}$, luego, con un seguimiento personalizado en cada caso.

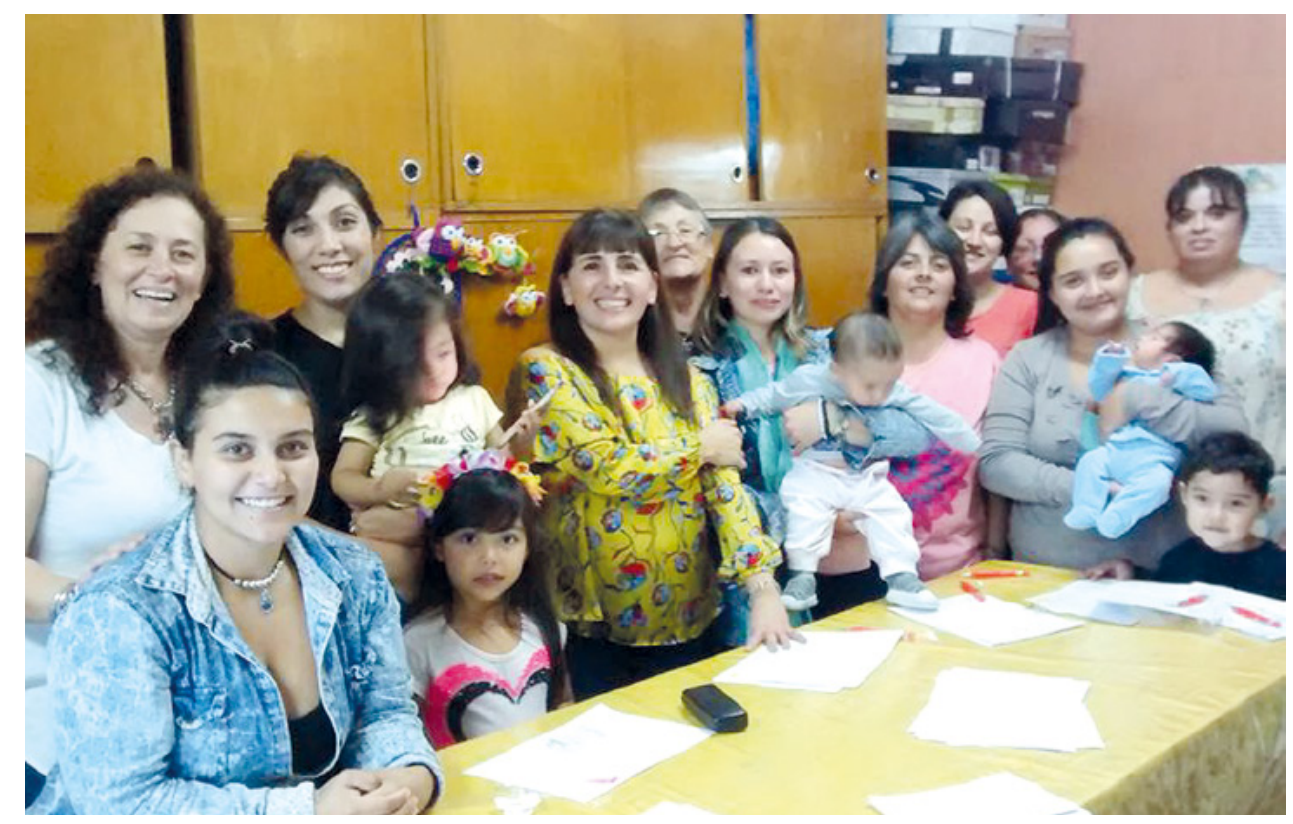

Figura 2. Mujeres que participaron del taller "Gestión de Proyectos creativos". Abril 2017. Fuente: Proyecto Esperanza Milani.

Por otro lado, la organización de un evento anual sobre "Mujer Emprendedora", en el cual se pudiera invitar a profesionales especializadas en el tema a disertar y, además, incluir las experiencias de las emprendedoras locales para que pudieran ser referentes cercanas para las demás mujeres de la localidad. 


\subsection{Comunicación y público objetivo}

Entre los objetivos principales de este segundo nivel se encontraban: llegar a todas las mujeres de Manfredi con información sobre Proyecto Esperanza Milani y desarrollar un sistema de comunicación que sea reconocible a partir de la invitación a compartir y generar un espacio propio.

\section{El enunciador, el yo del discurso, ofrece una mirada propia; una perspectiva, un lugar físico e ideológico desde donde ese yo interpela a un tú. Así como un discurso depende de la voz que lo sostenga, un enunciado visual es ofrecido desde una mirada particular a partir de la cual el destinatario -con su propia mirada- construye la representación. El punto de vista perceptivo del sujeto nunca es multifocal sino fijo, único y subjetivo. Desde esa posición espacial e ideológica, desde esa cosmovisión, se construye lo real y se pone en escena una enunciación determinada por índices de tiempo y espacio. En los enunciados visuales se presupone una figura de enunciador y de destinatario que nunca aparece explícita, aunque puede reconstruirse analizando el lugar desde donde habla el yo que, de modo correlativo, construye la ubicación del otro dentro del texto; dibuja, coordena a su destinatario. (López, 2015, p. 126).}

En este sentido, se propuso un intento de desplazamiento de ese "yo" que comunica (en ese momento, la coordinadora de Proyecto Esperanza Milani), para trabajar y elaborar en conjunto con las mujeres que asistían y/o eran egresadas del taller, manifestaciones visuales a partir de la reflexión sobre el significado del espacio y los modos en que se realizaban desde el compartir.

Se trabajaría en un espacio-taller donde se propondría la reflexión sobre la práctica, intentando decodificar luego esos conceptos en una creación individual o colectiva (podría trabajarse como cadáver exquisito, por ejemplo). Los resultados de estas producciones, serían fotografiados para ser imágenes de la campaña de difusión anual.

Los medios implicados serían la página de la organización en Facebook (pautando publicaciones con una segmentación a nivel local) y la impresión de un objeto de uso para el hogar (por ejemplo, un calendario) que se pautaría en conjunto con las mujeres durante el taller. Para la impresión de dicho objeto se buscaría un sponsor que pudiera costear los gastos, para que la entrega sea gratuita y llegara a la mayoría de los hogares de Manfredi. 
Además, se propuso que todas las gráficas de promoción de talleres y capacitaciones se realizaran con imágenes de las mujeres en situación de clase en el espacio del taller.

Se pensó, también, en la edición de un banner y folleto institucional que estuvieran disponibles en los momentos de encuentro, como participación en ferias o eventos organizados por Proyecto Esperanza Milani (como la jornada de los 25 de noviembre y la de Mujer Emprendedora).

\subsection{Vinculación con las organizaciones externas y el sector productivo}

Como se pudo visualizar en las respuestas a encuestas y entrevistas, las mujeres de la localidad de Manfredi postulaban que en el pueblo el rol de la mujer estaba muy ligado a las actividades domésticas (tanto en sus hogares como trabajando para terceros) y que en los comercios también eran empleadas como personal para la cocina o limpieza, pero en muy pocos casos para tareas administrativas y mucho menos técnico/profesionales específicas. También reconocían que la municipalidad había hecho poco para revertir esta situación, incluso cuando se habían ofrecido para realizar tareas de mantenimiento de calles, por ejemplo, de forma voluntaria (argumentando la institución que ese tipo de trabajos "no eran para la mujer").

De esta manera, se podía intuir una creencia popular de que en Manfredi no había posibilidades, que el cambio no dependía de uno, pero por sobre todo... que Manfredi estaba "aislado del mundo". Y que para conseguir un trabajo en donde uno pudiera realizarse, debería irse.

En este sentido, es que se intentó abordar la búsqueda de una estrategia para cumplir con ambos objetivos planteados, en términos de Burrel y Morgan (1980), desde una postura radical estructuralista: intentando comprender las tensiones y contradicciones intrínsecas, partiendo del supuesto de que la estructura de poder del pueblo busca mantener bajo control ciertos comportamientos para que sigan reproduciéndose (p. 609). 
La forma de trascender esta dominación sería la praxis: en el hacer podríamos dejar al descubierto esta "ilusión" de que no hay posibilidades de desarrollo en Manfredi. Pero... ¿cómo se lograría esto y qué tenía que ver con Proyecto Esperanza Milani? La organización había intentando una acción de inserción de las emprendedoras en el circuito de consumo a partir de la Asociación de Artesanos. Las deficiencias percibidas en esta acción tenían que ver con, en primer lugar, que la asociación organizaba eventos en la localidad donde no había una demanda real ni que pudiera hacer a un proyecto, en el que se fabrican este tipo de objetos, viable. Con demanda real se hacía referencia no sólo a cantidad de potenciales consumidores, sino al poder adquisitivo de dichos consumidores (al no darse una competencia real, las emprendedoras debían fijar sus precios muy por debajo de lo que se podían cobrar en otros lugares). Y cuando se traccionaba para ir a eventos en localidades vecinas, muchas mujeres no tenían los medios para trasladarse con los objetos (la producción de muñecos y materiales del stand) o no tenían disponibilidad de tiempo para hacerlo (tenían que estar en casa con su familia, por ejemplo).

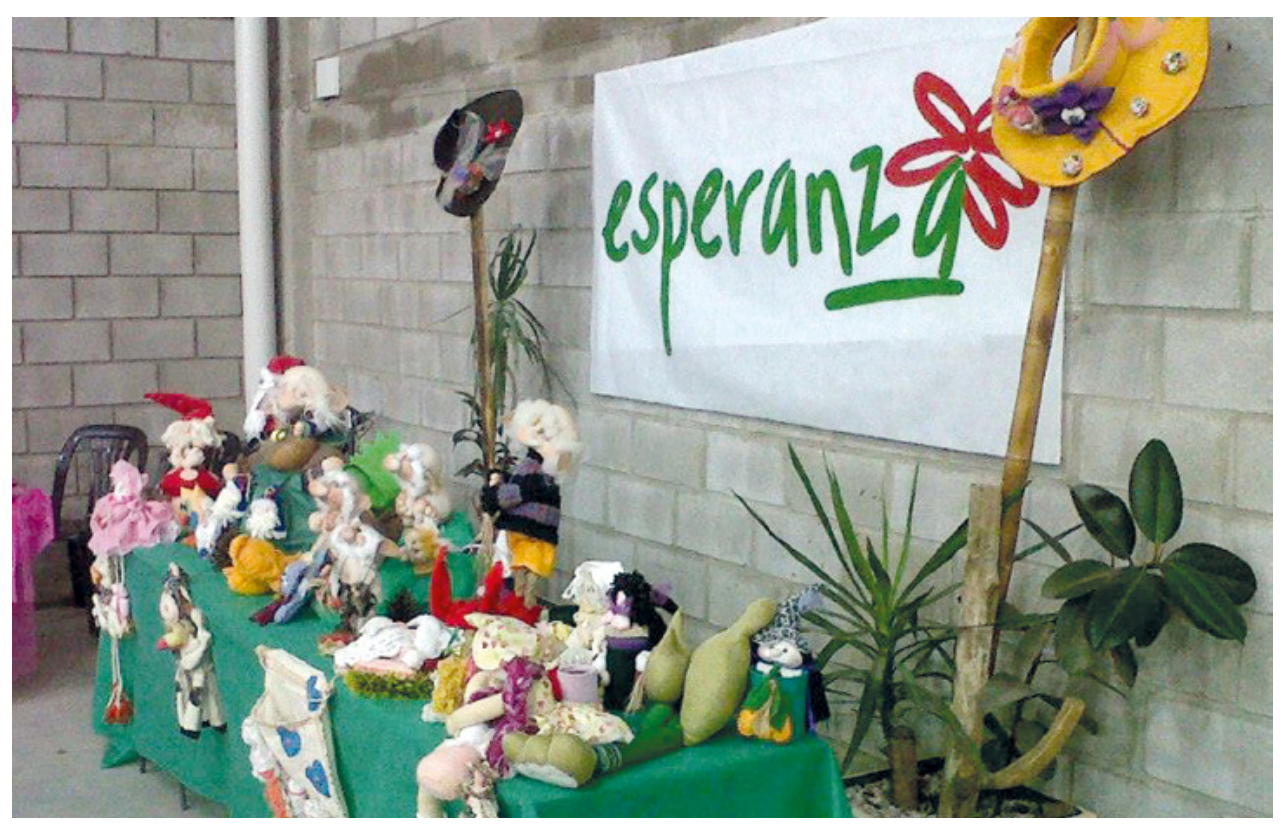

Figura 3. Stand de la agrupación en fiesta local por el Día Internacional de la Mujer. Marzo 2015. Fuente: Proyecto Esperanza Milani. 
En segundo lugar, se estimaba desacertado el haber elegido la palabra "artesanos" para la asociación. Si bien entendíamos que los productos elaborados contenían una alta carga de trabajo manual, los mismos podían ser realizados bajo un patrón, en serie y con medios industriales. Por lo que también podrían, trabajando en el desarrollo de una marca, comunicación, packaging, etc. ofrecerse como productos de diseño. Lo que fundamentamos a continuación desde el aporte que podría hacer el diseño desde su rol como institucionalizador, según Mónica Pujol (2005) en su artículo "Diseñando espacios de sentido":

\section{[...] la pieza diseñada es reconocida como un tipo de comunicación que se recorta dentro del conjunto de los discursos sociales, como un tipo de voz en particular. Como toda voz, implica sujetos hablando, sujetos que hablan entre sí. Pero, en el diseño estos sujetos nunca hablan desde su dimensión individual, siempre hablan desde su dimensión institucional. Los emisores que son descriptos en comunicaciones diseñadas siempre son institucionales. Aún en el portfolio diseñado para un artista se lo institucionaliza, poniendo aquello que lo individualiza en valor. Ya no se habla solo del artista en su dimensión individual, sino que se habla de su dimensión institucional poniendo su hacer en relación con los valores «universales» para esa sociedad del arte. [...] el diseño es el modo en que las organizaciones modernas hacen visibles, dentro de cánones institu- cionales, sus comunicaciones".}

¿Qué propusimos entonces? Una "re-semantización" de lo obvio. Para ejemplificar este concepto, se realizó una comparación entre dos casos: los productos realizados con la técnica amigurumi, comercializados por una de las alumnas (en adelante, "alumna") de Proyecto Esperanza Milani y una reconocida diseñadora en Argentina (en adelante, "diseñadora") ${ }^{5}$.

${ }^{5}$ Se evita mencionar los nombres para preservar la privacidad e identidad de ambas mujeres. 
Los productos de la diseñadora se vendían sólo en tiendas de "objetos de diseño" (algunas de estas tiendas tenían su versión online) y su precio oscilaba entre $\$ 350$ y $\$ 500$ (en productos similares al analizado). La alumna, intentaba vender sus productos en Manfredi, donde expresó que sólo podía trabajar a pedido y llegar a cobrar un objeto como el del ejemplo hasta $\$ 200$.

Ahora, ¿qué es lo que cambiaba entre un objeto y otro? Porque por lo que se podía apreciar, la técnica del amigurumi estaba perfectamente desempeñada en ambos casos (la puntada era prolija y la forma final del objeto era de fácil reconocimiento con el animal al que representaban, por ejemplo).

Lo que cambiaba era el imaginario creado en torno a cada objeto. El producto de la diseñadora, tenía nombre y marca: tenía identidad. Además, en ocasiones, la diseñadora escribía historias sobre sus productos en su blog lo que colaboraba en la creación de un relato en torno a ellos. Por nombrar sólo algunas características que hacían a esta "re-semantización" de lo obvio, y que podíamos encontrar ya desde un primer momento en la iluminación, puesta en escena, encuadre, etc. con los que eran tomadas las fotografías del objeto para comercializarlo en la web.

Entonces, se formulaba la pregunta: ¿era posible trabajar en conjunto con la alumna para agregar este valor a sus objetos y que pasaran de ser percibidos como "artesanías" a "objetos de diseño"? Sí. Pero aún faltaba una instancia más, ya que no sólo debíamos pensar en las características en las que se desarrollaban y presentaban los objetos, sino el contexto en el que luego eran insertados.

La propuesta, entonces, fue generar un nuevo actor en el sistema productivo que permitiera que las emprendedoras egresadas de Proyecto Esperanza Milani trabajaran desde sus hogares en Manfredi en la producción de los objetos; llegaran a mayor cantidad de personas de su público objetivo, el cual no estaba radicado en la localidad; no tuvieran que, necesariamente, movilizarse con objetos y stands hacia ferias fuera del pueblo para encontrar a su "target".

No era, entonces, el contexto en el que en ese momento lo proponía la Asociación de Artesanos (puestos en festivales locales). La propuesta final fue generar una tienda online de objetos de diseño, donde se pensará una interfaz virtual con características similares a otras tiendas del rubro ya posicionadas. 
La tienda debía constituirse como una empresa del sector privado. Se buscaría una política que pudiera financiar el proyecto o un inversionista. El constituirse de esta manera le otorgaría cierta autonomía y sería percibida por la sociedad como una entidad del sistema productivo en plena actividad comercial libre.

Se pensó en la modalidad virtual, porque podía gestionarse desde Manfredi, pero derribando las barreras geográficas, ampliando de esta manera el alcance a mayor cantidad de personas que podrían comprar, incluso, desde el exterior. Y derribando también los supuestos de que no podía haber desarrollo en la localidad.
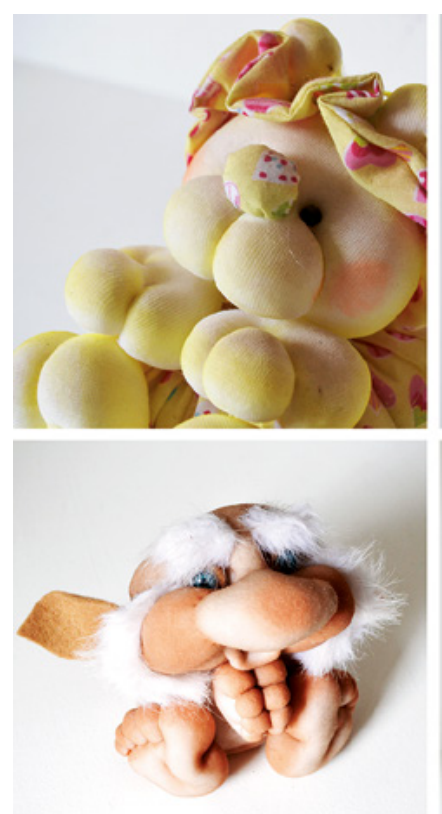
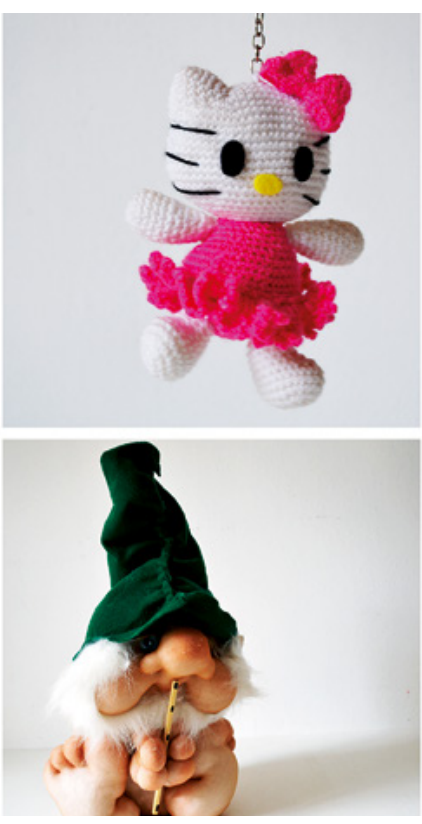
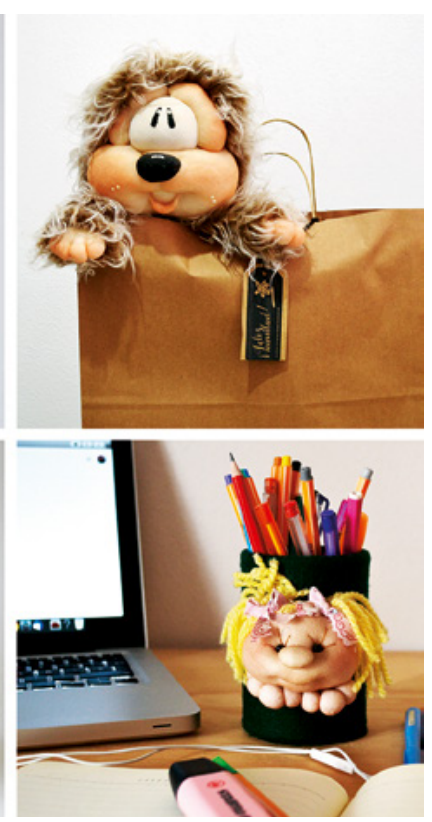

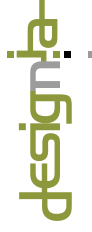

87

Figura 4. Fotografías de productos de las emprendedoras, como ejemplo para publicar en sitio web de comercio electrónico. 
La vinculación con Proyecto Esperanza Milani se daría a través de la formación de las emprendedoras para fabricar un determinado tipo de productos (con determinadas características que se definirían a partir del concepto de "objeto de diseño" que se comercializa en este tipo de tiendas) convirtiéndolas en proveedoras.

Se propuso, también, que a través de Proyecto Esperanza Milani las emprendedoras tramitaran su inscripción en AFIP (Administración Federal de Ingresos Públicos de Argentina) para que pudieran facturar y cobrar por depósito bancario. Que desarrollaran su marca personal, es decir, que no perdieran el reconocimiento por la autoría de sus objetos sino que siguieran sintiendo la propiedad y pertenencia de su proyecto.

Dichas prácticas contribuirían de manera indirecta y sin necesidad de hacer "publicidad" de las mismas, en el empoderamiento femenino. Y si se lograba establecer un ingreso fijo, esto también contribuiría a la percepción del entorno inmediato de la mujer con un emprendimiento que finalmente la dignificaría. 


\section{CONCLUSIONES}

En el contexto de la investigación y mirando hacia futuro, en torno a la tienda web, también podrían comercializarse otro tipo de productos que implicaran a las emprendedoras como protagonistas. Por ejemplo, la edición de videos tutoriales o de libros con diferentes técnicas "paso a paso" para la confección de muñecos. Pero, por sobre todo, se podría crear una plataforma tipo blog donde cada emprendedora pudiera contar su experiencia, para que de esa manera se convierta en un potencial referente cercano y tangible para otras mujeres de Manfredi.

Podríamos continuar enumerando estrategias y alternativas de intervención. A lo largo de este proceso y en la propia construcción del relato de la experiencia, desde la propuesta teórica inicial a la superación del trabajo de campo, hubo una recurrente intención de "tejer" con una perspectiva situada. Desde lo disciplinar y profesional, a lo temporal y espacial, también en términos socio-económicos y políticos.

\section{La construcción de la sustentabilidad en contexto es un conjunto de decisiones guiadas por el proyecto, en un marco de pragmatismo, que reinterpreta los compromisos que subsume el concepto de sustentabilidad, según las particularidades locales, sin perder la visión de las totalidades que configuran los escenarios regulatorios, y las partes que se asumen como unidades pertinentes y constitutivas de tales totalidades. (Galán, 2014, p. 55).}

Desde el planteo de la pregunta, ¿es posible la elaboración de una propuesta de diseño estratégico en el territorio, desde el empoderamiento con perspectiva de género, en localidades pequeñas? Hasta la toma de partido, "Compartiendo empoderamiento" y la consecuente propuesta estratégica.

El relato de esta experiencia representa una de las tantas formas en las que podría manifestarse una intervención para el desarrollo local. Se esperaba, en caso de que fuera exitosa, que pudiera replicarse en otros rubros y contextos. En definitiva, se esperaba a partir de estas prácticas, la institucionalización de un sector que en los pueblos estaría "pasando desapercibida": el diseño. 


\section{REFERENCIAS BIBLIOGRÁFICAS}

Arriagada, I. (2005). Dimensiones de la pobreza y políticas desde una perspectiva de género. Revista de la CEPAL, 85. 101-113. ISSN 02520257. Recuperado de: https://repositorio.cepal.org/bitstream/ handle/11362/11002/085101113_es.pdf [Consultado por última vez el 1 de abril de 2020].

Barthes, R. (1993). El placer del texto. Madrid, España: Siglo XXI editores.

Dirección General de Estadísticas y Censos, Secretaría de Fortalecimiento institucional, Secretaría General de la Gobernación. Gobierno de la Provincia de Córdoba. Recuperado de: https://datosestadistica.cba. gov.ar/dataset/censo-2010-resultados-definitivos [Consultado por última vez el 29 de marzo de 2020].

Flores Fahara, M. (2004). Implicaciones de los paradigmas de investigación en la práctica educativa. Revista Digital Universitaria, 5 (1), 2-9. Recuperado de: http://www.revista.unam.mx/vol.5/num1/art1/ene_art1. pdf [Consultado por última vez el 1 de abril de 2020].

Franco, J. E. \& Muñóz, H. \& Lesmes, L. (2008). Creatividad, innovación y diseño estratégico, herramientas de competitividad. Actas de diseño 4, Año II, Vol. 4, 99-100. ISSN 1850-2032. Recuperado de: https:// fido.palermo.edu/servicios_dyc/publicacionesdc/archivos/12_libro.pdf [Consultado por última vez el 1 de abril de 2020].

Frascara, J. (2012). El diseño de comunicación (1a ed. 3 a reimp.). Buenos Aires, Argentina: Infinito.

Galán, B. (2014). Diseño, proyecto y desarrollo: Miradas del período 2007-2010 en argentina y latinoamérica. Buenos Aires, Argentina: Wolkowicz. 
Hendon, W. S., et al. (1980). Economic Policy for the Arts. Cambridge: ABT Books.

Jasso Villazul, J. (2011). Emprendedor y emprendedurismo. Reflexiones y consideraciones de una teoría en construcción. Hunab Ku Economía \& Negocios, 2. 93-99.

Ledesma, M. (2003). El diseño gráfico, una voz pública (de la comunicación visual en la era del individualismo). Buenos Aires, Argentina: Editorial Argonauta.

Leiro, R. (2006). Diseño: Estrategia y gestión. Buenos Aires, Argentina: Infinito.

Libby-Hawk, J. \& Mills, L. \& Wynhoven, U. \& Gula, L. (2011). Principios para el empoderamiento de las mujeres: La igualdad es buen negocio. Nueva York, Estados Unidos: ONU Mujeres y Oficina del Pacto Mundial de la ONU.

López, M. A. (2015). Espacio representado: espacio significado: Del espacio como creación subjetiva. En D. A. Vidable (Coord.), Espacio social y espacio simbólico, territorios del diseño (pp. 121-144). Buenos Aires, Argentina: Wolkowicz editores.

Manzini, E. (2015). Cuando todos diseñan: una introducción al diseño para la innovación social. Madrid, España: Experimenta Theoria.

Morgan, G. (1980). Paradigms, Metaphors, and Puzzle Solving in Organization Theory. Administrative Science Quarterly, 25(4), 605-622. doi:10.2307/2392283

Pujol, M. Diseñando espacios de sentido. Foroalfa. ISSN 1851-5606. Recuperado de: https:/foroalfa.org/ articulos/disenando-espacios-de-sentido [Consultado por última vez el 29 de marzo de 2020].

Ramos, C. (2017). Los paradigmas de la investigación científica. Avances En Psicología, 23(1), 9-17. doi:10.33539/ avpsicol.2015.v23n1.167

Sabino, C. (2002). El proceso de investigación. Venezuela: Editorial Panapo.

Sol, J. (1999). La Guerra de las PYMES. Buenos Aires, Argentina: Editorial Del Nuevo Extremo.

Torns, T. (2008). El trabajo y el cuidado: cuestiones teóricometodológicas desde la perspectiva de género. EMPIRIA. Revista de Metodología de las Ciencias Sociales, (15),53-73. ISSN: 1139-5737. Disponible en: https://www.redalyc.org/articulo.oa?id=2971/297124045003 [Consultado por última vez el 1 de abril de 2020]. 